DOI: $10.1002 /$ marc. 201600760

Article Type (Communication)

res

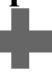

Doubly Dynamic Self-Healing Materials Based on Oxime Click Chemistry and

\title{
Boronic Acids
}

Joe Collins, Milena Nadgorny, Zeyun Xiao, Luke A. Connal*

Joe Collins, Mitena Nadgorny, Dr Zeyun Xiao, Dr Luke A. Connal

The Department of Chemical and Biomolecular Engineering, The University of Melbourne, 3010, Australia.

E-mail: luke.connal@unimelb.edu.au

The dynamic covalent characteristics of oxime and boronate ester bonds have been explored. A small excess of a competing aldehyde under acidic conditions resulted in oxime-polymer degradation from high molecular weights $(30 \mathrm{kDa})$ to low molecular weight oligomers $(2.2 \mathrm{kDa})$. The dynamic nature of oxime bonds imparted oxime-crosslinked hydrogels with self-healing properties and the incorporation of phenyl boronic acid groups into the hydrogel network provided a platform for hydrogel functionalisation. The addition of a polyphenol (tannic acid) proved a facile means to incorporate a second, dynamic covalent crosslinking network through boronate ester formation which, owing to the increase in the degree of crosslinking, was found to nearly double the hydrogel strength (storage modulus increased from 4.6 to $8.5 \mathrm{kPa}$ ). Finally, the tannic-acid crosslinking network was selectively degraded returning the hydrogel storage modulus to its initial value and providing a means for the synthesis of materials with tunable mechanical properties.

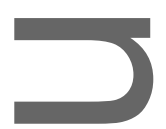

This is th uuth $\mathrm{r}$ manuscript accepted for publication and has undergone full peer review but has not been throug - copyediting, typesetting, pagination and proofreading process, which may lead to differences between this version and the Version of Record. Please cite this article as doi: 10.1002/marc.201600760.

This article is protected by copyright. All rights reserved. 

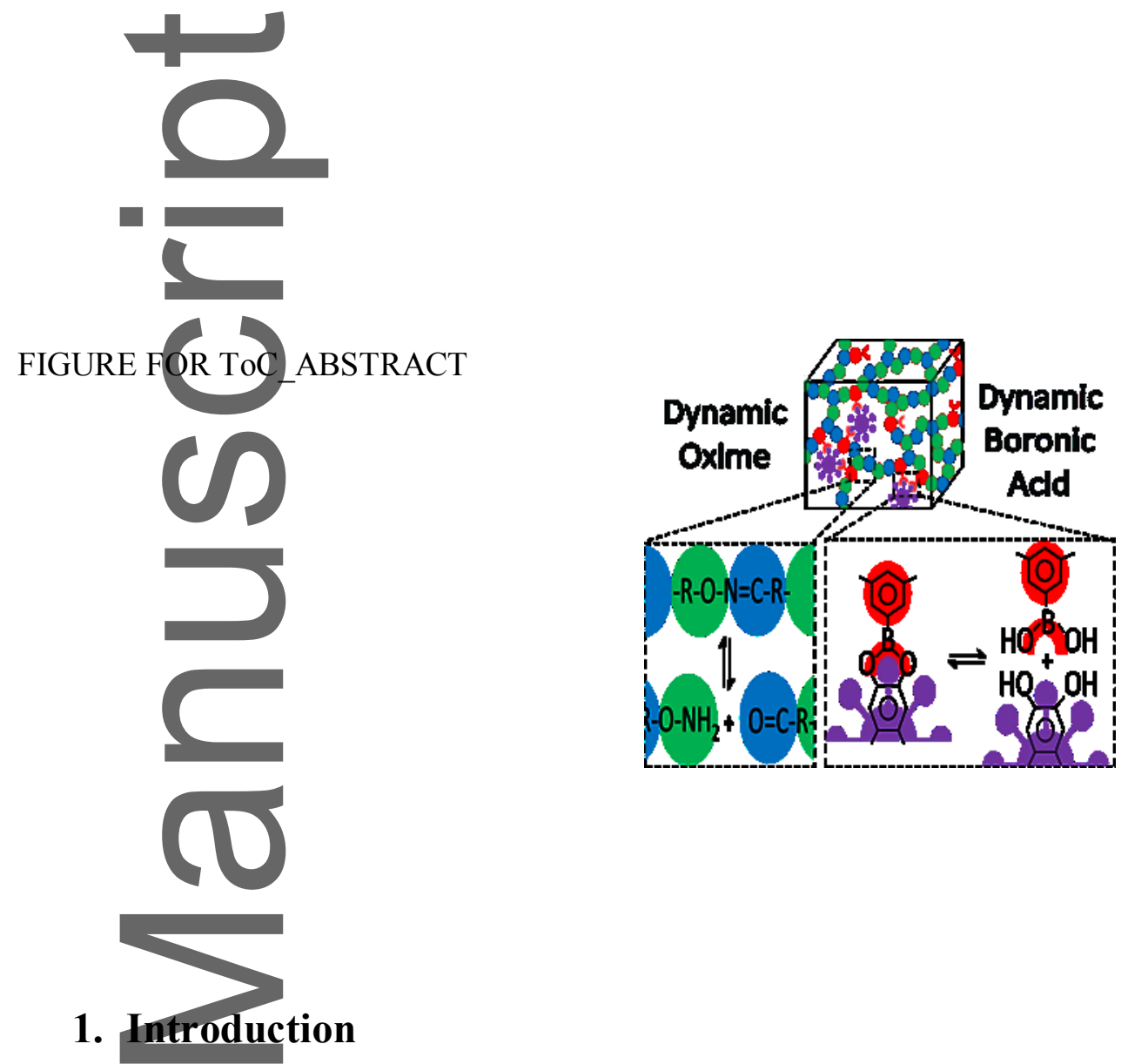

Nature is reliant on complex dynamic chemistries, in particular, biology utilises dynamic covalent chemistry to control catalysis and to achieve self-assembly in DNA and proteins. ${ }^{[1-3]}$ Compared to non-covalent interactions (H-bonding, $\pi$-stacking etc.) dynamic covalent bonds exhibit higher strength and enable a greater degree of control over the reaction equilibrium. ${ }^{[4,5]}$ An impressive suite of synthetic materials have been prepared based on dynamic chemistries such as imine,${ }^{[6-13]}$ hydrazone, ${ }^{[14,15]}$ Diels-Alder,${ }^{[16-18]}$ disulphide,${ }^{[8,19-21]}$ boronate ester ${ }^{[22-26]}$ and olefin metathesis ${ }^{[27]}$ which show potential for drug discovery, ${ }^{[28]}$ drug delivery, ${ }^{[29,30]}$ regenerative medicine, ${ }^{[14,31]}$ self-healing materials ${ }^{[11-13,26,32-34]}$ and shapememory polymers. ${ }^{[18,35]}$ 
The oxime bond, formed through the condensation between an aldehyde/ketone and a hydroxylamine, remains as one of the most unexplored dynamic covalent chemistries. Displaying favourable reaction conditions (high efficiency, chemoselectivity, formation in aqueous solvents and water as the only side-product) and bond properties (high hydrolytic stability) ${ }^{[36]}$ oxime chemistry has been used almost exclusively for bioconjugation. ${ }^{[37]}$ Owing to the demand for more versatile chemistry and more environmentally friendly means of synthesis the oxime ligation has recently seen an astonishing increase in materials science applications. ${ }^{[38]}$ Over the last few years oxime chemistry has been used in the development of bioadhesives, ${ }^{[39,40]}$ self-healing hydrogels, ${ }^{[41]}$ for step-growth polymer synthesis ${ }^{[42]}$ and for the creation of dynamic macromolecular assemblies. ${ }^{[43]}$

Recently, materials possessing multiple orthogonal dynamic chemistries have been developed enabling the synthesis of intricate macromolecules which respond to multiple stimuli to achieve a desired response. ${ }^{[4]}$ Compared to a singly dynamic chemistry, the incorporation of multiple dynamie linkages allows for the fine-tuning of a material response to a particular stimuli or the incorporation of a dual-responsive nature which would be valuable for applications in drug delivery, sensing, surface patterning and materials science. The incorporation of multiple dynamic chemistries into a single material has been achieved with various orthogonal reactions: oxime and Diels-Alder, ${ }^{[45]}$ imine and ester ${ }^{[6]}$ and impressively, hydrazone, disulphide and boronate ester. ${ }^{[46]}$

Herein, we present an investigation into the dynamic properties of oxime-based materials. High molecular weight step-growth polymers $(30 \mathrm{kDa})$, synthesized via oxime click chemistry, can be degraded by careful control of the reaction equilibrium. We also demonstrate the versatility of oxime chemistry to develop self-healing hydrogels, again by controlled modulation of the oxime equilibrium. The hydrogel was shown to possess intrinsic self-healing prop- 
erties confirmed through rheological characterisation. Finally, the oxime-based hydrogel was modified to incorporate a phenyl boronic acid moiety thereby creating a doubly dynamic material. The addition of a polyphenol, tannic acid, led to the formation of a boronate ester dynamic covalent crosslinking network within the oxime hydrogel which was found to increase the hydrogel strength. We also demonstrate the facile and orthogonal reversibility of the boronate ester network to recover the initial gel.

\section{Experimental Section}

Chemicals were purchased from Sigma Aldrich or Alfa Aesar and used without further purification. 1H-NMR spectra were recorded using a Varian $400 \mathrm{MHz}$ spectrometer. For differential refractive index (DRI) traces, DMF was used as an eluent and the size exclusion chromatography (SEC) analysis was conducted on a Shimadzu liquid chromatography system equipped with a Shimadzu RID-10 refractometer $(\lambda=633 \mathrm{~nm})$ and Shimadzu SPD-20A UV-vis detector using two Phenomenex Phenogel columns (5 $\mu \mathrm{m}$ bead size, 104 and $106 \AA$ porosity) in series operating at $70^{\circ} \mathrm{C}$. DMF with $0.05 \mathrm{~mol} \mathrm{~L}$ $1 \mathrm{LiBr}(>99 \%$, Aldrich) was employed as the mobile phase at a flow rate of $1 \mathrm{~mL}$ min-1. The system was calibrated using polystyrene standards. All samples were filtered through $0.45 \mu \mathrm{m}$ nylon filters prior to injection. Molecular weight distributions (PDIs) were calculated relative to linear polystyrene standards. Rheological properties of the gels were characterized by controlled strain rheometer with $40 \mathrm{~mm}$ parahlel plate geometry (AR-G2, TA Instruments).

Tetraethylene glycol bishydroxylamine (M1): Synthesis of tetraethylene glycol bishydroxylamine (M1) was carried out according to a reported literature procedure. ${ }^{[47]} 1 \mathrm{H}-\mathrm{NMR}$ (400 MHz, CDC13): $\delta$ 4.24 (t, J = $4 \mathrm{~Hz}, 4 \mathrm{H} ; \mathrm{CH} 2), 3.82(\mathrm{t}, \mathrm{J}=4 \mathrm{~Hz}, 4 \mathrm{H} ; \mathrm{CH} 2), 3.71$ (s, 8H; CH2).

Dibenzaldehyde Tetraethylene Glycol (M2): Tetraethylene glycol (TEG) (5.00 g, 25.7 mmol), 4formyl benzoic acid (7.92 g, $52.8 \mathrm{mmol}$ ) and dimethylaminopyridine (DMAP) (0.47g, $3.85 \mathrm{mmol})$ were dissolved in DCM (100 mL). N,N'-Dicyclohexylcarbodiimide (DCC) (10.88g, $52.7 \mathrm{mmol})$ in 
DCM $(20 \mathrm{~mL})$ was added to the solution dropwise. The reaction was left to stir for 24 hours at room temperature. The crude reaction mixture was concentrated under reduced pressure then filtered. The filtrate was-purified by column chromatography using hexane/ethyl acetate $(80 / 20)$. The product was collected as a white solid (10.47g, 89\%). 1H-NMR (400 MHz, CDCl3): $\delta 10.07$ (s, 2H; HCO), 8.18 (d, J = 8 Hz, 4H; Ar), 7.91 (d, J = $8 \mathrm{~Hz}, 4 \mathrm{H} ; \mathrm{Ar}), 4.47$ (t, J = $4 \mathrm{~Hz}, 4 \mathrm{H} ; \mathrm{CH} 2), 3.82$ (t, J = $4 \mathrm{~Hz}, 4 \mathrm{H}$; $\mathrm{CH} 2), 3.66(\mathrm{~m}, \mathrm{~J}=4 \mathrm{~Hz}, 8 \mathrm{H} ; \mathrm{CH} 2)$.

Glycerol Ethoxylate Tribenzaldehyde (M3): Glycerol ethoxylate (2.00 g, $2.00 \mathrm{mmol})$, 4-formyl benzoic acid $(1.00 \mathrm{~g}, 6.66 \mathrm{mmol})$ and dimethylaminopyridine (DMAP) $(0.04 \mathrm{~g}, 0.33 \mathrm{mmol})$ were dissolved in DCM (100 mL). N,N'-Dicyclohexylcarbodiimide (DCC) (1.37 g, $6.66 \mathrm{mmol})$ in DCM (50 $\mathrm{mL}$ ) was added to the solution dropwise. The reaction was left to stir for 24 hours at room temperature. The crude reaetion mixture was concentrated under reduced pressure then filtered. The filtrate was purified by column chromatography using DCM/Methanol (7\% MeOH). The product was collected as a colorless oil (1.4 g, 50\%). 1H-NMR (400 MHz, CDCl3): $\delta 10.08$ (s, 3H; HCO), 8.19 (d, J $=8 \mathrm{~Hz}, 6 \mathrm{H} ; \mathrm{Ar}), 7.93(\mathrm{~d}, \mathrm{~J}=8 \mathrm{~Hz}, 6 \mathrm{H} ; \mathrm{Ar}), 4.48$ (t, J= $4 \mathrm{~Hz}, 6 \mathrm{H} ; \mathrm{CH} 2), 3.82(\mathrm{t}, \mathrm{J}=4 \mathrm{~Hz}, 6 \mathrm{H} ; \mathrm{CH} 2)$, 3.60 (bs, $82 \mathrm{H} ; \mathrm{CH} 2)$.

Oxime Polymer Synthesis (P1): M2 in DMF (150 mmolL-1) was added to solid M1 in equimolar amounts together with a desired volume of aniline $(40 \mathrm{~mol} \%)$. The polymerization was left to run for 3 hours at $60^{\circ} \mathrm{C}$. Following polymerization, the product was repeatedly precipitated in hexane and distilled to afford the product as a tacky, amber solid. 1H-NMR (400 MHz, CDCl3): $\delta 8.12$ (s, 2H; $\mathrm{O}=\mathrm{NCH}), 8.03(\mathrm{~d}, \mathrm{~J}=8 \mathrm{~Hz}, 4 \mathrm{H} ; \mathrm{Ar}), 7.62(\mathrm{~d}, \mathrm{~J}=8 \mathrm{~Hz}, 4 \mathrm{H} ; \mathrm{Ar}), 4.46(\mathrm{t}, \mathrm{J}=4 \mathrm{~Hz}, 4 \mathrm{H} ; \mathrm{CH} 2), 4.35$ (t, J $=4 \mathrm{~Hz}, 4 \mathrm{H} ; \mathrm{CH} 2), 3.80$ (q, J = 4 Hz, 8H; CH2), 3.67 (s, 16H; CH2).

Oxime Hydrogel Synthesis (G1): M3 (0.661 g, $0.473 \mathrm{mmol})$ and M1 (0.210 g, $0.709 \mathrm{mmol})$ each dissolved in a minimum amount of $\mathrm{MeOH}$ were mixed together before aniline $(51.7 \mu \mathrm{L}, 0.567 \mathrm{mmol})$ was introdueed. The reaction mixture was heated to $60^{\circ} \mathrm{C}$ and gelation was observed to occur within 5 minutes. 
Boronic Acid Functional Hydrogel Synthesis $\left(\mathbf{G}_{\text {Boron }}\right)$ : M3 (0.560 g, 0.400 mmol), M1 (0.196 g, $0.662 \mathrm{mmol})$ and 3,5-diformyl phenyl boronic acid $(12.57 \mathrm{mg}, 0.071 \mathrm{mmol})$ each dissolved in minimum amount of $\mathrm{MeOH}$ were mixed together before aniline $(20 \mu \mathrm{L}, 0.219 \mathrm{mmol})$ was introduced. The reaction mixture was heated to $60^{\circ} \mathrm{C}$ and gelation was observed to occur within 5 minutes.

Reversible-Gel-Sol Transition (RG-1): TFA ( $2 \mathrm{~mL}, 26 \mathrm{mmol})$ and DCM (2 mL) were added to G1. After approximately 2 hours G1 had changed from a gel to a solution. Following the gel-sol transition, the solution was placed in the fume hood and the TFA allowed to evaporate affording gel reformation $(\mathrm{RG}-1)$.

Doubly Dynamic Crosslinking through Boronate Ester Formation $\left(\mathbf{G}_{\text {Boron-T }}, \mathbf{G}_{\mathrm{Boron}-\mathrm{C}}\right)$ : Tannic acid (60 mg, $0.035 \mathrm{mmol}$ ) was dissolved in a $\mathrm{pH} 8.14$ phosphate buffer $(10 \mathrm{~mL})$ before $\mathrm{G}_{\text {Boron }}$ was introduced to the-solution. The sample was left to incubate overnight to allow sufficient tannic acid binding within the hydrogel $\left(\mathrm{G}_{\mathrm{Boron}-\mathrm{T}}\right)$. A similar procedure was undertaken for the synthesis of $\mathrm{G}_{\mathrm{Boron}-}$ c. Catechol (777 mg, $7.06 \mathrm{mmol})$ was dissolved in a $\mathrm{pH} 8.14$ phosphate buffer $(10 \mathrm{~mL})$ before $\mathrm{G}_{\text {Boron }}$ was introduced to the solution. The sample incubated three times with fresh catechol solutions, twice for two hour periods and once overnight to ensure sufficient tannic acid release and catechol binding within the hydrogel $\left(\mathrm{G}_{\text {Boron-C }}\right)$.

Rheological Characterization: Rheological properties of the gels were characterized by controlled stress rheometer with $40 \mathrm{~mm}$ parallel plate geometry (AR-G2, TA Instruments). The linear viscoelastic region of the gels was determined by dynamic strain sweeps performed at a frequency of $10 \mathrm{rad} / \mathrm{s}$ at $25^{\circ} \mathrm{C}$. Mechanical properties of the gels were examined by dynamic frequency sweep at $25^{\circ} \mathrm{C}$ and $0.5 \%$ strain, which is within the linear viscoelastic region, as was previously determined by strain sweep experiments.

Self-Healing Analysis by Rheology: Self-healing of oxime-hydrogels was studied by a stress ramp up from 0.01 to $16,000 \mathrm{~Pa}$ performed at a frequency of $10 \mathrm{rad} \mathrm{s}-1$ at $25^{\circ} \mathrm{C}$. The sample was placed between rheometer plates and deformed under stress until a rupture within the gel was observed as indicated by a sharp drop in the storage modulus. The stress was then removed and the sample al- 
lowed to recover for 10 minutes. After recovery, the experiment was repeated to trace the changes in the gels dynamic moduli.

\section{Results and Discussion}

To synthesize difunctional A-A and B-B type molecules for step-growth polymerization ethylene glycol-based bis-hydroxylamine and dialdehyde monomers were prepared. Tetraethylene glycol bishydroxylamine, M1, was prepared utilising the Mitsunobu reaction followed by deprotection with hydrazine. Dibenzaldehyde tetraethylene glycol, M2, was prepared via a carbodi-imide coupling. The combination of monomers M1 and M2 with aniline (40 mol \%) at $60^{\circ} \mathrm{C}$ yielded an oxime linked polymer (P1) which was analysed though ${ }^{1} \mathrm{H}-$ NMR and SEC (Figure 1A).

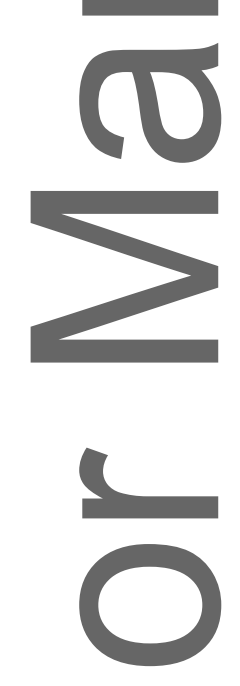

A)

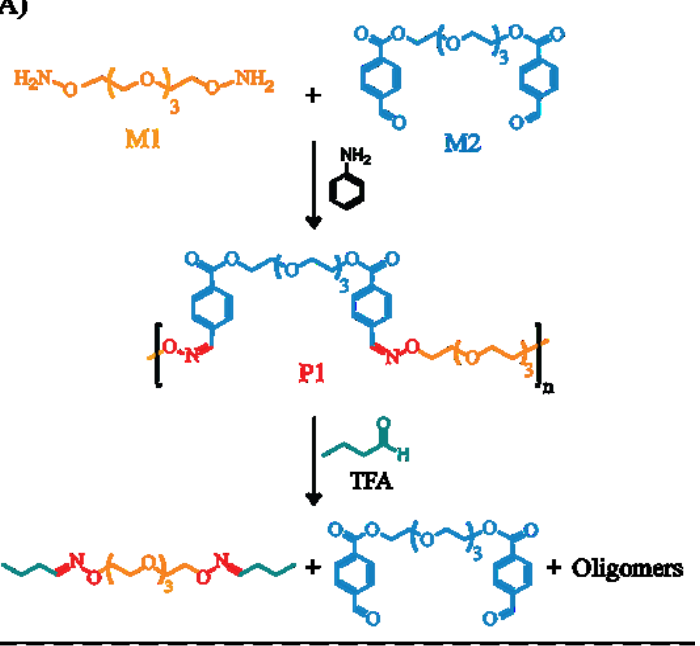

B)

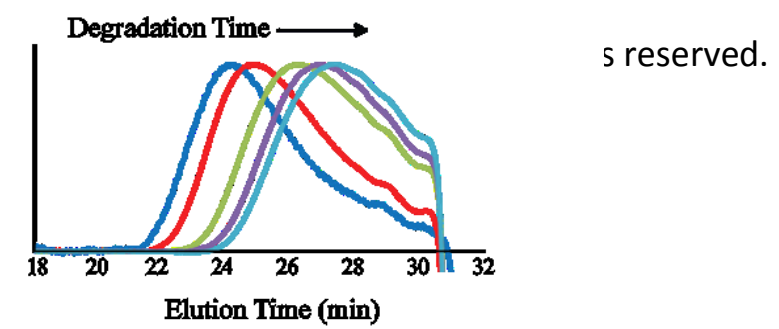




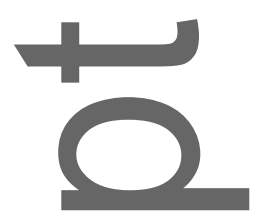

$\square$

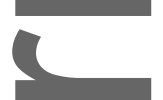

Figure 1. (A) Synthetic

Figure 1. (A) Synthetic scheme for the synthesis of P1 from monomers M1 and M2 and P1 degradation resulting from the reaction with butyraldehyde under acidic conditions, and (B) corresponding SEC traces. Initial molecular weight was calculated to be $30 \mathrm{kDa}$ (blue) which decreased to $22 \mathrm{kDa}$ after 4 hours (red), to $15.5 \mathrm{kDa}$ after $24 \mathrm{hrs}$ (green), to $10.7 \mathrm{kDa}$ after $48 \mathrm{hrs}$ (purple) and to $8.7 \mathrm{kDa}$ after $96 \mathrm{hrs}$ (light blue) at $60^{\circ} \mathrm{C}$.

The successful formation of the oxime polymer was confirmed through ${ }^{1} \mathrm{H}-\mathrm{NMR}$, as a new singlet peakat $8.12 \mathrm{ppm}$ appears which can be attributed to the new oxime proton, and SEC was utilised to calculate a molecular weight of $30 \mathrm{kDa}$ (see Figure $\mathrm{S} 1$ for ${ }^{1} \mathrm{H}-\mathrm{NMR}$ characterisation and Figure S2 for SEC).

The high $M_{w}$ oxime polymers can be degraded by control of the oxime equilibrium via two distinct mechanisms: transoximination or hydrolysis. Degradation by transoximination can be achieved through the addition of butyraldehyde (BA), under acidic conditions at $60^{\circ} \mathrm{C}$, forcing the reaction back towards the starting materials and successfully degrading P1 to low molecular weight oligomers within one week. Using 5 equivalents of trifluoroacetic acid (TFA) and BA, P1 reduced from 30.0 to $22.0 \mathrm{kDa}$ after 4 hours, to $15.5 \mathrm{kDa}$ after $24 \mathrm{hrs}$, to 10.7 $\mathrm{kDa}$ after $48 \mathrm{hrs}$ and to $8.7 \mathrm{kDa}$ after $96 \mathrm{hrs}$ at $60^{\circ} \mathrm{C}$ (Figure $1 \mathrm{~b}$ ). 
The degradation of P1 was also monitored by ${ }^{1} \mathrm{H}-\mathrm{NMR}$ which showed a decrease in the intensity of the butyraldehyde aldehyde proton peak and a shifting of the TEG chain protons (Figure S3). The escape of TFA and BA was minimised through the use of a condenser. When no heating was applied the rate of polymer degradation reduced and a molecular weight of $21.2 \mathrm{kDa}$ was calculated after $96 \mathrm{hrs}$. Polymer degradation was also achieved via hydrolysis through themanipulation of the equilibrium by the addition of a large excess of TFA (95 equivalents, reduction to $10.3 \mathrm{kDa}$ after $96 \mathrm{hrs}$ at $60^{\circ} \mathrm{C}$, Figure $\left.\mathrm{S} 4\right)$ and through an alternative transoximination pathway through the addition of an excess of M1 under acidic conditions (5 equivalents, reduction to $2.2 \mathrm{kDa}$ after $96 \mathrm{hrs}$ at $60^{\circ} \mathrm{C}$, Figure S5) indicating the various methods to achieve oxime reversibility and hence polymer degradation.

In order to create a new oxime-linked hydrogel and investigate its self-healing/dynamic abilities a trifunctional aldehyde monomer was synthesized, M3. Again, simple carbo-dimide coupling between 4-formyl benzoic acid and glycerol ethoxylate was utilized to incorporate the aldehyde functionality which allowed for successful oxime-hydrogel synthesis, G1. Gelation occurred within 5 minutes at a M1:M3 monomer ratio of 2:3 with 40 mol\% aniline and heating to $60^{\circ} \mathrm{C}$ (Figure 2A).

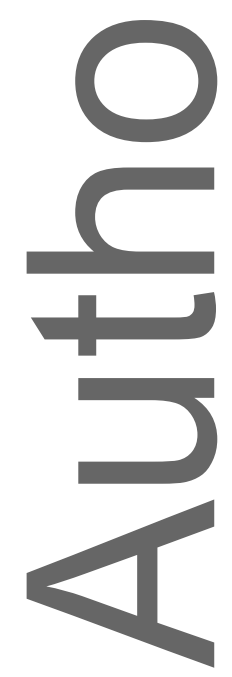




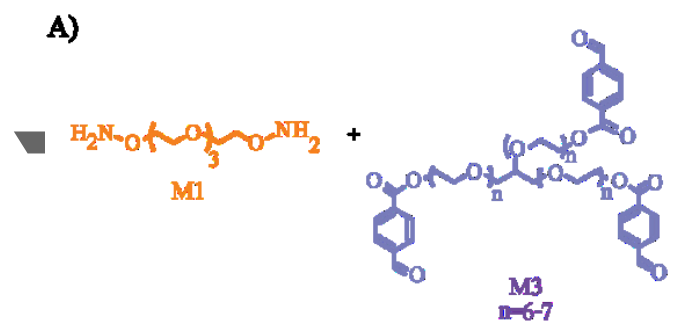

B)
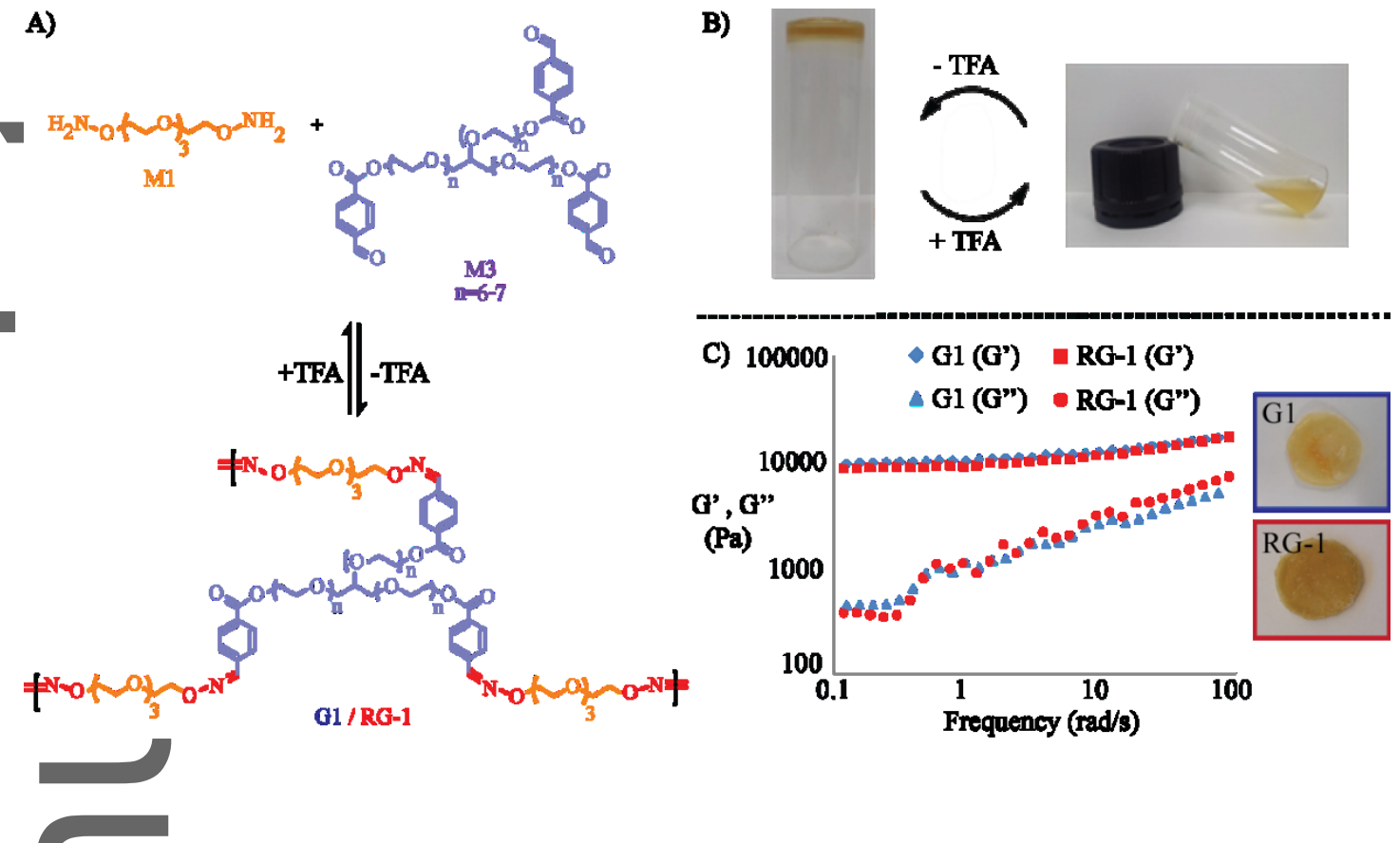

Figure 2. (A) Synthetic scheme for the synthesis and reversibility of oxime-linked hydrogels, $\mathbf{G} 1$ and RG-1 through addition of TFA and removal by evaporation. RG-1 represents recycling of the gel G1 after evaporation of TFA. (B) Images of the reversible sol-gel transition stimulated by TFA addition and evaporation.(C) Rheological characterisation of G1 (blue diamonds) and RG-1 (red squares) showing a negligible decrease in the storage modulus during the TFA recycling procedure.

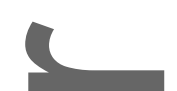

The dynamic nature of oxime bonds allows for the degradation of the polymer network affording a gel-soltransition. Recently, Sumerlin and co-workers reported that the addition of an excess of the monofunctional hydroxylamine, O-(-tetrahydro-2H-pyran-2yl)hydroxylamine, with TFA achieved a gel-sol transition of an oxime cross-linked hydrogel. ${ }^{[41]}$ We propose a reversible system for the degradation/re-formation of oxime hydrogels which exploits the volatility of TFA. Following gel degradation, TFA evaporation is expected to allow for the recovery of the polymer network. This was confirmed as, following 
the addition of an excess of TFA yielding complete gel degradation after $2 \mathrm{hrs}$ at room temperature, the gel successfully re-formed following acid evaporation (Figure 2B).

The storage modulus of the initial oxime hydrogel (G1) was examined by rheology and found to be $9.4 \mathrm{kPa}$ (equilibrium modulus as indicated by the plateau region of the curve) which reduced slightly to $8.7 \mathrm{kPa}$ (ca. $7.5 \%$ decrease) during the recycling process (RG-1) (Figure 2C). This very small reduction in storage modulus during the recycling process indicates the potential for the re-use of oxime-based materials without significant loss in mechanical performance.

Oxime derived self-healing was first reported by Sumerlin and co-workers in the development of oxime-crosslinked acrylamide hydrogels. ${ }^{[41]}$ However, not all oxime-based materials have proven to be self-healing. ${ }^{[14,48]}$ The self-healing ability of G1 and RG-1 were investigated and analysed by both standard methods and rheometery. Gels were cut into two halves and physically pressed together which, after approximately 3 hours, successfully re-healed. Qualitatively, the re-healed gel was found to withstand significant force applied perpendicular to the original cut as well as to support itself under gravity (Figure 3A-D).
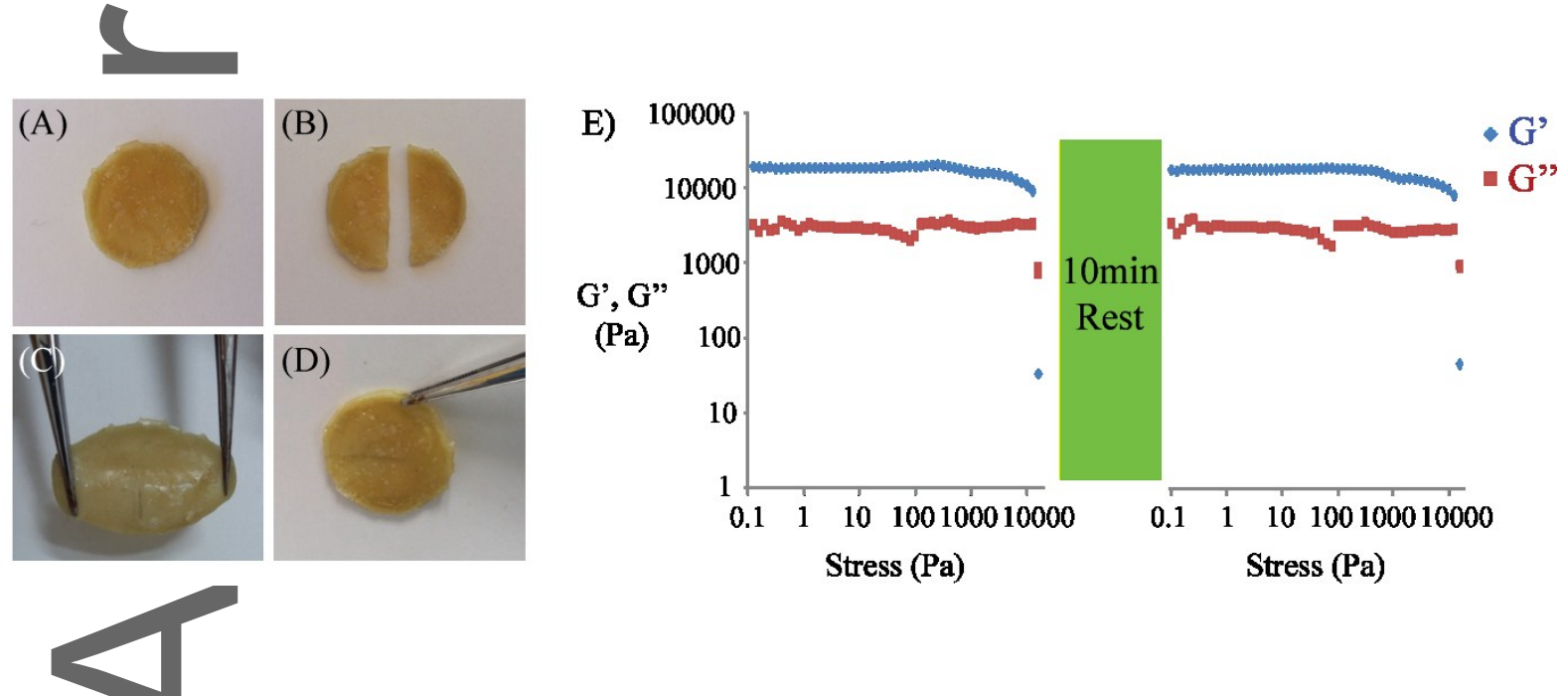

Figure 3. (A) The initial gel G1. (B) G1 cut into two halves. (C) Healed gel. The two halves were placed back together, after approximately 3 hrs self-healing had occurred and the healed gel was 
found to withstand significant force applied perpindiular to the original cut line. (D) The reformed gel was able to support itself under gravity. These images of RG-1 demonstrate successful self-healing.

(E) Rheological characterisation of G1 self-healing. Stress on the gel was increased until failure was observed as indicated by a drop in storage modulus occuring at approximately $16 \mathrm{kPa}$. After gel failure stress was removed and the gel was left for 10 minutes to allow self-healing. Self-healing was confirmed by the return of the storage modulus to its initial value.

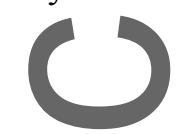

The self-healing ability of $\mathbf{G 1}$ was confirmed by rheology. Stress on the gel was ramped up until structural failure was observed, as indicated by a drop in storage modulus. At approximately $16 \mathrm{kPa}$ a sharp drop in the storage modulus is observed, and additionally the value for the loss modulus becomes higher than the storage modulus, indicating that the mechanical integrity of the gel is lost and the network is broken. Following this, the stress on the gel was removed to allow the gel to re-heal. After approximately 10 minutes the storage modulus was shown to recover back to the initial value indicating successful self-healing (Figure 3E).

Combining multiple dynamic chemistries into a single material has the potential to create next generation materials with tuneable properties. One pairing that holds promise is the combination of boronic acid and oxime bonds. It was recently reported that oxime formation is accelerated by proximal boronic acid groups,${ }^{[49,50]}$ however the dynamic properties of the two has yet to be explored. The synthesis of various boronic acid functional polymers has recently been reviewed, ${ }^{[25]}$ here we present a new synthetic method to create boronic acid functional polymers using commercial starting materials and investigate the dynamic properties of boronic acid bonds within oxime-based hydrogels.

To synthesize a doubly dynamic oxime/boronic acid material we incorporated phenyl boronic acid groups into the oxime hydrogel. This enabled us to form a second dynamic plat- 
form to allow a doubly crosslinked network to be formed and readily degraded thereby creating a material with tuneable mechanical properties. Through the incorporation of $10 \mathrm{~mol} \%$ diformyl phenyl boronic acid (a commercially available dialdehyde) into the oxime hydrogel a doubly dynamic material was successfully synthesized $\left(\mathbf{G}_{\text {Boron }}\right)$. Due to the change in reactant ratio caused by the addition of the dialdehyde functional boronic acid, $\mathbf{G}_{\text {Boron }}$ reduced in mechanicalstrength when compared to $\mathrm{G} 1\left(\mathrm{G}^{\prime}=4.6\right.$ and $9.4 \mathrm{kPa}$ respectively).

Double network hydrogels, traditionally prepared through the synthesis of two separate but interpenetrating networks, show potential for the synthesis of tough hydrogels. ${ }^{[51,52]}$ Through the use of dynamic boronate ester bonds we can prepare two covalently linked, yet reversible, crosslinking networks. The addition of the poly-phenol molecule tannic acid provided a means of crosslinking the boronic acid groups within the hydrogel.

Through the formation of this boronate ester network, a doubly dynamic, doubly crosslinked hydrogel was prepared $\left(\mathbf{G}_{\text {Boron-T}}\right)$. The incorporation of the boronate ester-tannic acid network increased the degree of cross-linking and hence the storage modulus of $\mathbf{G}_{\text {Boron- }}$ was found to be nearly double that of $\mathbf{G}_{\text {Boron }}\left(G^{\prime}=8.5\right.$ and $4.6 \mathrm{kPa}$ respectively). We then demonstrated the reversible nature of boronate ester-tannic acid network by the addition of an excess of catechol, an aromatic diol not capable of crosslinking between boronic acid groups

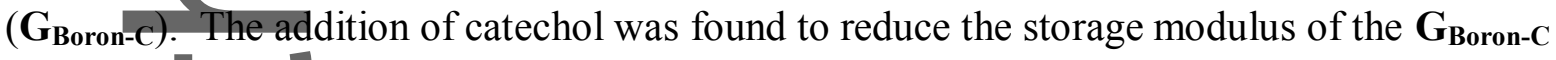
back to its original value thereby confirming the removal of the tannic acid and break down of the second crosslinking network (Figure 4).

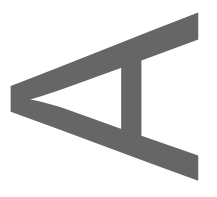



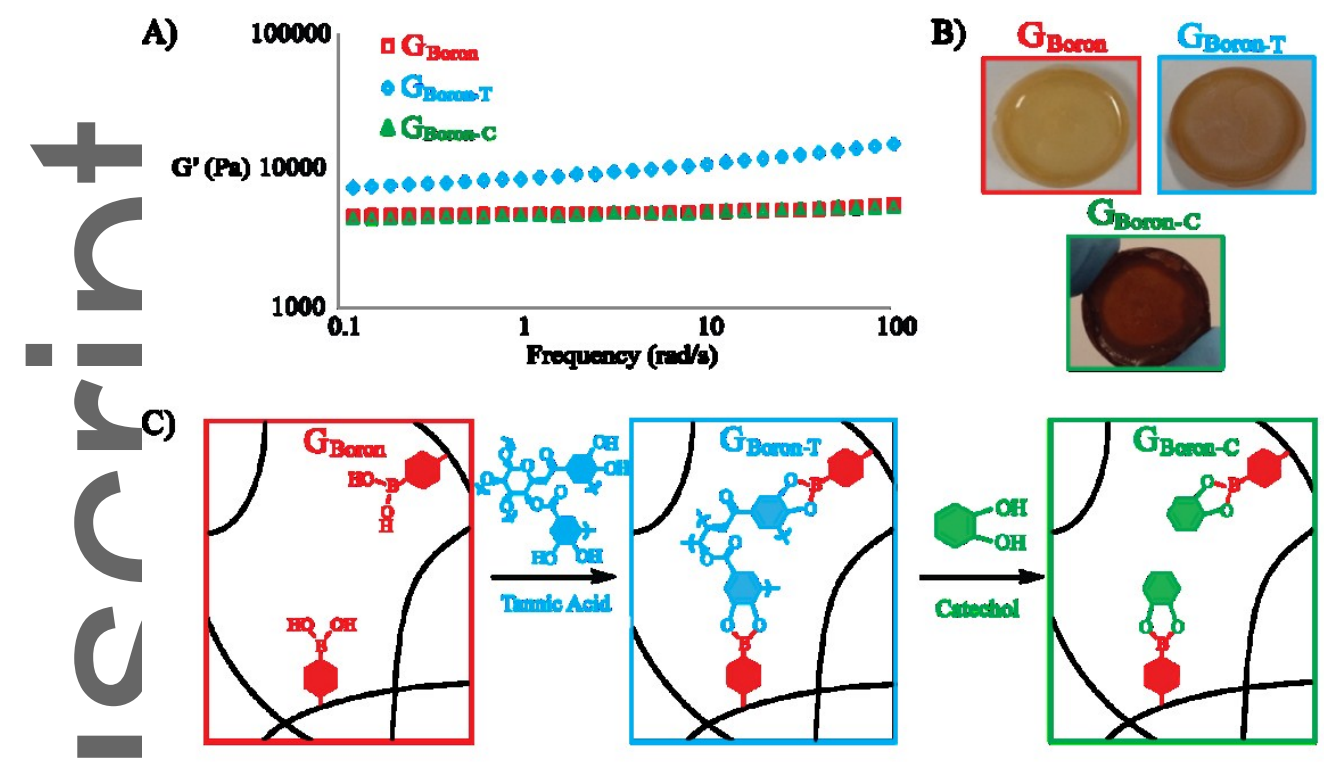

Figure 4. (A) Rheological characterisation of the storage moduli of $\mathbf{G}_{\text {Boron }}$ (red squares), $\mathbf{G}_{\text {Boron-T }}$ (blue diamonds) and $\mathbf{G}_{\text {Boron-C }}$ (green triangles). (B) Images of $\mathbf{G}_{\text {Boron }}, \mathbf{G}_{\text {Boron-T }}$ and $\mathbf{G}_{\text {Boron-C }}$. (C) Schematic represention of binding withing each hydrogel network. An initial storage modulus of $4.6 \mathrm{kPa}$ is calculated for $\mathbf{G}_{\text {Boron }}$ which nearly doubles upon tannic acid crosslinking to yield $\mathbf{G}_{\text {Boron-T }}$ with a storage modulus of $8.5 \mathrm{kPa}$. The addition of catechol removes the tannic acid and returns the storage modulus of the hydrogel back to its initial value.

\section{Conclusion}

In summary, we have demonstrated the dynamic properties of oxime-based materials. We explored the development of degradable polymers and recyclable hydrogels capable of selfhealing. We show relatively stable oxime bonds and slow degradation profiles. This attractive property creates opportunities for oxime-based materials in biomedical application requiring longer residence times or slow, controlled release profiles.

By controlling the reaction equilibrium we also demonstrated the reversible nature of oxime-based hydrogels. These self-healing gels showed excellent recovery and successful recycling of the oxime-based materials. 
Finally, the orthogonal nature of the oxime bond was demonstrated through the addition of a second dynamic covalent network using phenylboronic acid. The doubly dynamic gel was formed by reaction with a polyphenol, through boronate ester formation in the presence of stable oxime bonds, and the reverse process was demonstrated thus creating a doubly dynamic covalent network. The boronic acid platform allows for functionalisation with a wide range of molecules and exemplifies the versatile nature of the oxime bond and how this can be exploited for the synthesis of highly complex, stimuli-responsive materials.

\section{↔}

\section{Supporting Information}

Supporting Information is available from the Wiley Online Library or from the author

Acknowledgements: This work was supported by the Victorian Endowment for Science, Knowledge and Innovation (LAC)

Received: Month XX, XXXX; Revised: Month XX, XXXX; Published online:

((For PPP, use "Accepted: Month XX, XXXX" instead of "Published online")); DOI:

10.1002/mare.((insert number)) ((or ppap., mabi., macp., mame., mren., mats.))

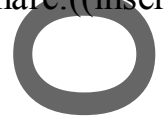

Keywords: (oxime, polymer, hydrogel, boronic acid, self-healing)

\section{REFERENCES}

[1] A. C. Eliot, J. F. Kirsch, Annu. Rev. Biochem. 2004, 73, 383.

[2] C. Khosta, R. S. Gokhale, J. R. Jacobsen, D. E. Cane, Annu. Rev. Biochem. 1999, 68, 219.

[3] P.J.Hogg, Trends Biochem. Sci. 2003, 28, 210.

[4] S. J. Rowan, S. J. Cantrill, G. R. L. Cousins, J. K. M. Sanders, J. F. Stoddart, Angew. Chemie Int. Ed. 2002, 41, 898.

[5] Y. Jin, C. Yu, R. J. Denman, W. Zhang, Chem. Soc. Rev. 2013, 42, 6634. 
[6] K. Fukuda, M. Shimoda, M. Sukegawa, T. Nobori, J.-M. Lehn, Green Chem. 2012, 14, 2907.

[7] Y.-H. Ma, J. Yang, B. Li, Y.-W. Jiang, X. Lu, Z. Chen, Polym. Chem. 2016, 7, 2037.

[8] D. A. Fulton, M. E. Bracchi, Chem. Commun. 2015, 51, 11052.

[9] E. R.L. Brisson, Z. Xiao, L. Levin, G. V Franks, L. A. Connal, Polym. Chem. 2016, 7, 1945.

[10] E. R. L. Brisson, Z. Xiao, L. A. Connal, Aust. J. Chem. 2016, 69, 705.

[11] P. Taynton, K. Yu, R. K. Shoemaker, Y. Jin, H. J. Qi, W. Zhang, Adv. Mater. 2014, 26, 3938.

[12] Z. Q. Lei, P.Xie, M. Z. Rong, M. Q. Zhang, J. Mater. Chem. a 2015, 3, 19662.

[13] A Chao, I. Negulescu, D. Zhang, Macromolecules 2016, 49, 6277.

[14] N. Boehnke, C. Cam, E. Bat, T. Segura, H. D. Maynard, Biomacromolecules 2015, 16, 2101.

[15] A. Dirksen, S. Dirksen, T. M. Hackeng, P. E. Dawson, J. Am. Chem. Soc. 2006, 128, 15602.

[16] P. J. Boul, P. Reutenauer, J. M. Lehn, Org. Lett. 2005, 7, 15.

[17] P. Reutenauer, E. Buhler, P. J. Boul, S. J. Candau, J. M. Lehn, Chem. - A Eur. J. 2009, 15, 1893.

[18] M. Fan, J. Liu, X. Li, J. Zhang, J. Cheng, Ind. Eng. Chem. Res. 2014, 53, 16156.

[19] Y. Nakai, A. Takahashi, R. Goseki, H. Otsuka, Polym. Chem. 2016, 7, 4661.

[20] A. Rekondo, R. Martin, A. Ruiz de Luzuriaga, G. Cabañero, H. J. Grande, I. Odriozola, Mater. Horizons 2014, 1, 237.

[21] E.-K. Bang, M. Lista, G. Sforazzini, N. Sakai, S. Matile, Chem. Sci. 2012, 3, 1752.

[22] J. J. Cash, T. Kubo, A. P. Bapat, B. S. Sumerlin, Macromolecules 2015, 48, 2098.

[23] A. R. Narkar, B. Barker, M. Clisch, J. Jiang, B. P. Lee, Chem. Mater. 2016, $28,5432$.

[24] J.-C. Lai, J.-F. Mei, X.-Y. Jia, C.-H. Li, X.-Z. You, Z. Bao, Adv. Mater. 2016, 28, 8277.

[25] G. Vancoillie, R. Hoogenboom, Polym. Chem. 2016, DOI 10.1039/C6PY00775A.

[26] C. C.Deng, W. L. A. Brooks, K. A. Abboud, B. S. Sumerlin, ACS Macro Lett. 2015, 4, 220.

[27] M. Schuster, S. Blechert, Angew. Chemie Int. Ed. English 1997, 36, 2036.

[28] O. Ramström, J.-M. Lehn, Nat. Rev. Drug Discov. 2002, 1, 26.

[29] Y. Shao, W. Huang, C. Shi, S. T. Atkinson, J. Luo, Ther. Deliv. 2012, 3, 1409.

[30] L. Qiu, C. Y. Hong, C. Y. Pan, Int. J. Nanomedicine 2015, 10, 3623.

[31] H. Wang, S. C. Heilshorn, Adv. Mater. 2015, 1.

[32] Y. Yang, M. W. Urban, Chem. Soc. Rev. 2013, 42, 7446.

[33] J. M. Lehn, Aust. J. Chem. 2010, 63, 611.

[34] D. L. Taylor, M. in het Panhuis, Adv. Mater. 2016, DOI 10.1002/adma.201601613.

[35] J. R. Kumpfer, S. J. Rowan, J. Am. Chem. Soc. 2011, 133, 12866.

[36] J. Kalia, R.T. Raines, Angew. Chemie - Int. Ed. 2008, 47, 7523.

[37] S. Uhrich, D. Boturyn, A. Marra, O. Renaudet, P. Dumy, Chem. - A Eur. J. 2014, 20, 34.

[38] J. Collins, Z. Xiao, M. Müllner, L. A. Connal, Polym. Chem. 2016, 7, 3812.

[39] G. N. Grover Garcia, J., Nguyen, M.M., Zanotelli, M., Madani, M.M., Christman, K.L., Adv. Healthc. Mater. 2015, 4, 1327.

[40] S. Ghosh, J.D. Cabral, L. R. Hanton, S. C. Moratti, Acta Biomater. 2016, 29, 206.

[41] S. Mukherjee, M. R. Hill, B. S. Sumerlin, Soft Matter 2015, 11, 6152.

[42] J. Collins, Z. Xiao, A. Espinosa-Gomez, B. P. Fors, L. A. Connal, Polym. Chem. 2016, 7, 2581

[43] S.Mukherjee, A. P. Bapat, M. R. Hill, B. S. Sumerlin, Polym. Chem. 2014, 5, 6923.

[44] A. Wilson, G. Gasparini, S. Matile, Chem. Soc. Rev. 2014, 43, 1948.

[45] S. Mukherjee, W. L. A. Brooks, Y. Dai, B. S. Sumerlin, Polym. Chem. 2016, 7, 1971.

[46] S. Lascano, K.-D. Zhang, R. Wehlauch, K. Gademann, N. Sakai, S. Matile, Chem. Sci. 2016, 


\section{7,4720 .}

[47] F. Taraballi, L. Russo, C. Battocchio, G. Polzonetti, F. Nicotra, L. Cipolla, Org. Biomol. Chem. 2014, 12, 4089.

[48] N. Kuhl, M Abend, S. Bode, U. S. Schubert, M. D. Hager, J. Appl. Polym. Sci. 2016, 133, 1.

[49] D. Gillingham, Org. Biomol. Chem. 2016, 7606.

[50] P. Schmidt, C. Stress, D. Gillingham, Chem. Sci. 2015, 6, 3329.

[51] H. J.Zhang, T.L. Sun, A. K. Zhang, Y. Ikura, T. Nakajima, T. Nonoyama, T. Kurokawa, O. Ito, H. Ishitobi, J. P. Gong, Adv. Mater. 2016, 4884.

[52] V. X. Truong, M. P. Ablett, S. M. Richardson, J. A. Hoyland, A. P. Dove, J. Am. Chem. Soc. 2015, 137, 1618 .

The dynamic covalent characteristics of the oxime bond has been explored. Through equilibrium manipulation polymer degradation and hydrogel self-healing was achieved. By exploiting the orthogonal nature of the oxime ligation, doubly dynamic hydrogels incorporating a boronate ester-tannic acid crosslinking network were produced creating materials with tunable mechanical properties

Joe Collins, Milena Nadgorny, Zeyun Xiao, Luke A. Connal*

\section{Doubly Dynamic Self-Healing Materials Based on Oxime Click Chemistry and Boronic Acids}

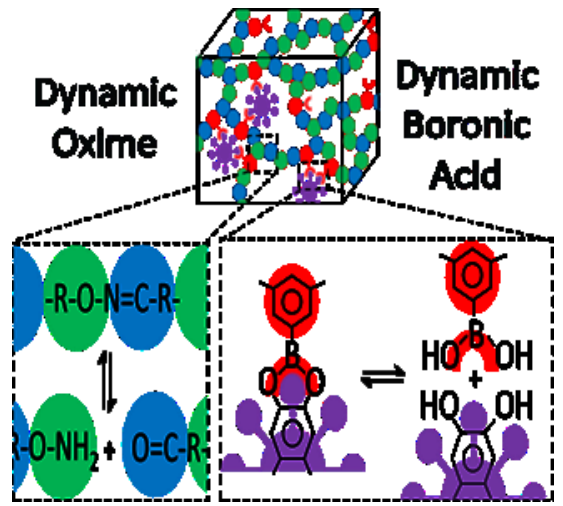




\section{Supponting Information}

for Macromol. Rapid Commun., DOI: 10.1002/marc.2013\#\#\#\#\#

\section{Doubly Dynamie Self-Healing Materials Based on Oxime Click Chemistry and Boronic Acids} Joe Collins, ${ }^{a}$ Milena Nadgorny, ${ }^{a}$ Zeyun Xiao, ${ }^{a}$ Luke A. Connal ${ }^{a}$.
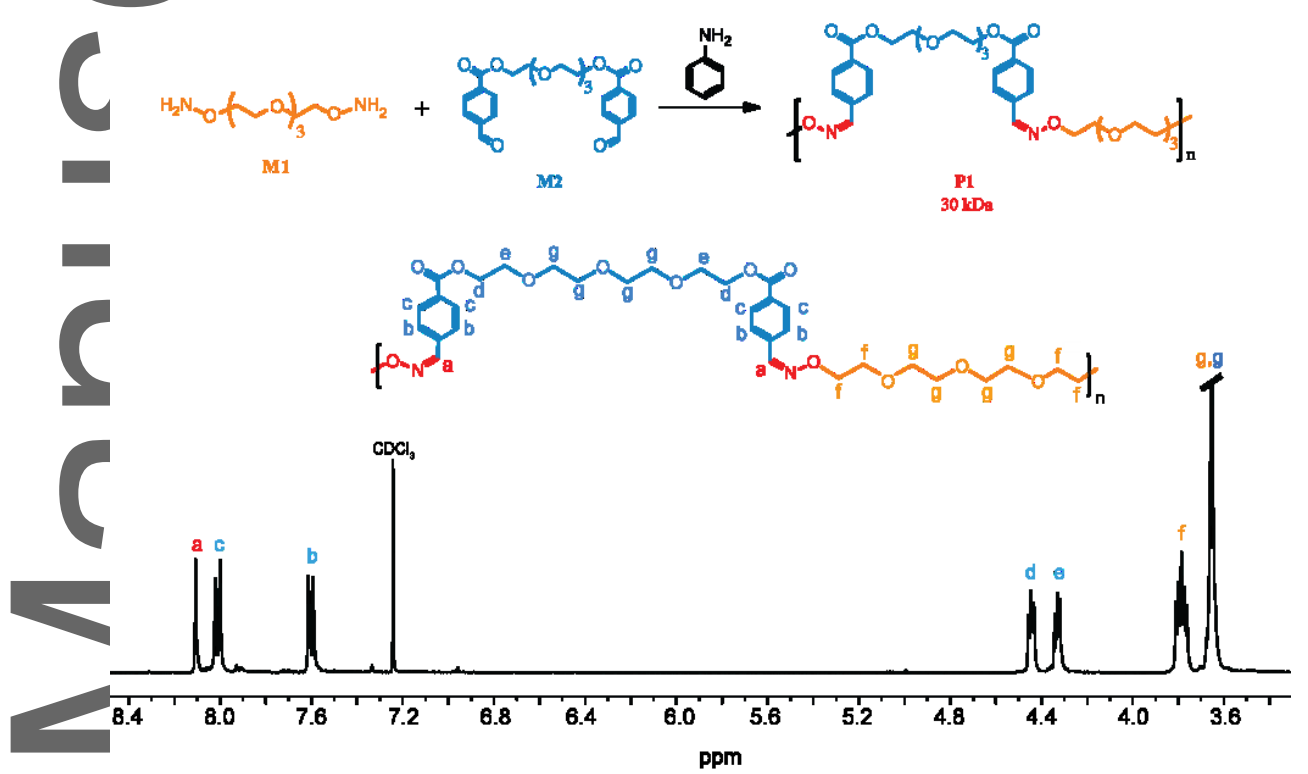

Figure S1.Synthesis and ${ }^{1} \mathrm{H}-\mathrm{NMR}$ characterisation of oxime-linked polymer P1. Two doublets at 8.03 and $7.62 \mathrm{ppm}$ ( $\mathrm{b}$ and $\mathrm{c}$ ) are attributed to the aromatic benzyl protons, the two triplets at 4.46 and $4.35 \mathrm{ppm}$ ( $\mathrm{d}$ and e) are attributed to the terminal protons of the TEG chain adjacent to the carbonyl group while the quintet at $3.80 \mathrm{ppm}$ (f) is attributed to the terminal protons of the TEG chain adjacent to the oxime bond. Finally, the singlet at $3.67 \mathrm{ppm}(\mathrm{g})$ is attributed to the middle chain TEG protons.
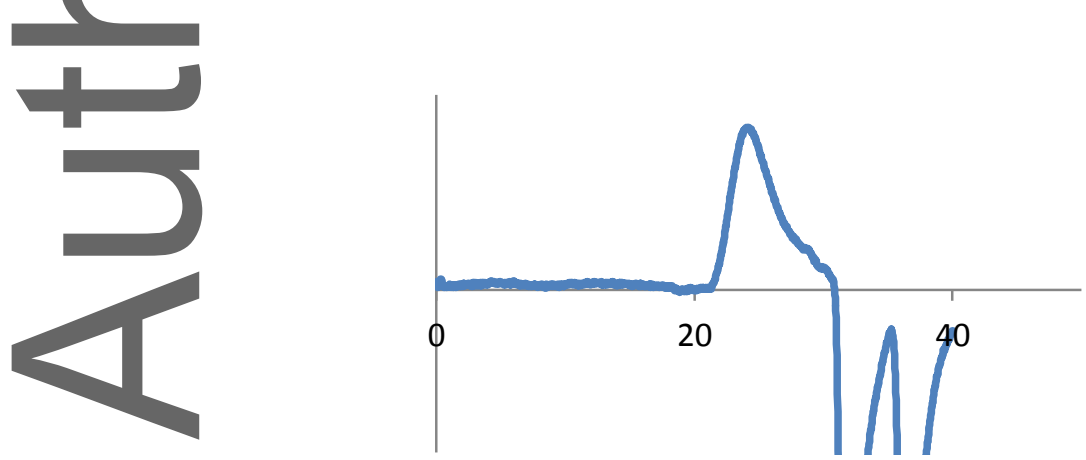

Figure S2. SEC trace of P1. SEC was used to calculate a molecular weight of $30 \mathrm{kDa}$ for P1 (Figure S2) indicating the very high efficiency of oxime chemistry. 


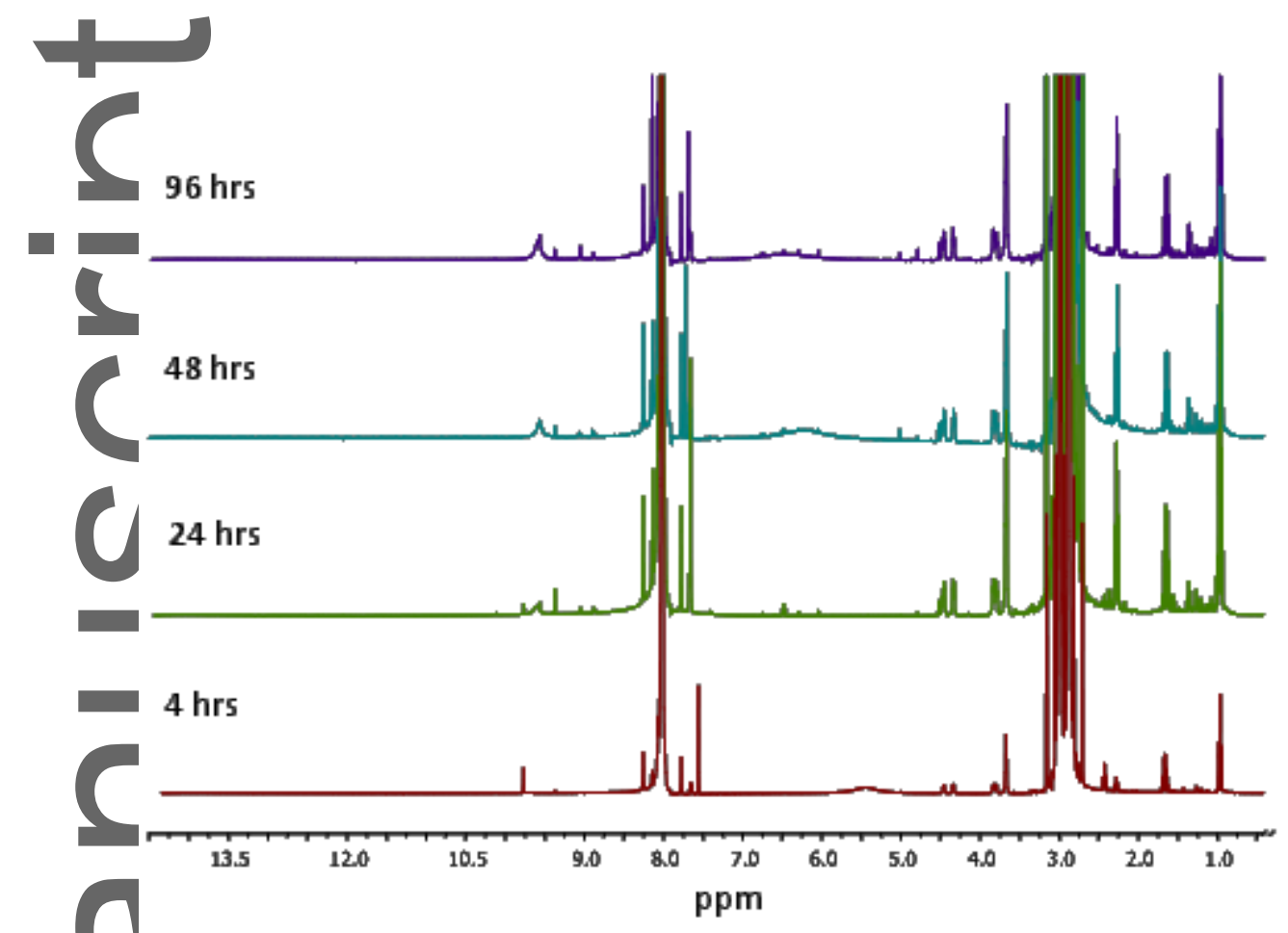

Figure S3. H-NMR spectra of P1 degradation with 5eq of butyraldehyde and TFA at $60^{\circ} \mathrm{C}$. Spectra recorded after $4 \mathrm{hr}$ (red), $24 \mathrm{hrs}$ (green), $48 \mathrm{hrs}$ (blue) and $96 \mathrm{hrs}$ (purple). The reduction in the butyraldehyde aldehyde peak at $9.77 \mathrm{ppm}$ and splitting of the TEG protons between $3.5-4.5 \mathrm{ppm}$ confirms the degradation of $\mathbf{P 1}$.
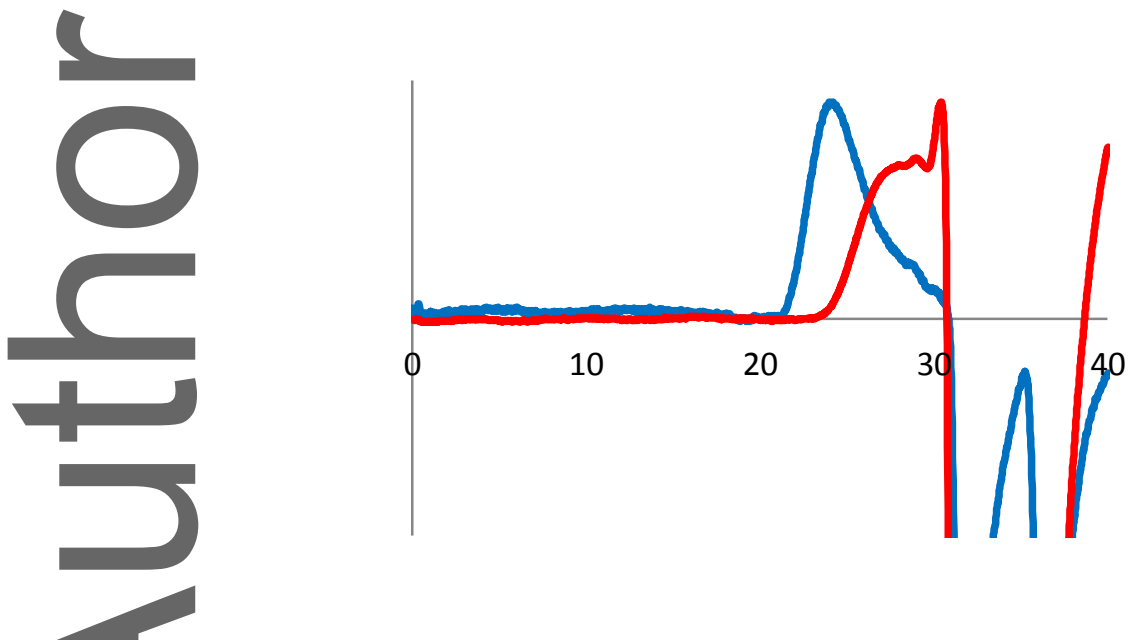

Figure S4. SEC trace of $\mathbf{P 1}$ before degradation, $30 \mathrm{kDa}$, (blue) and following degradation in the presence of 95 eq. of TFA, reduction to $10.3 \mathrm{kDa}$ after $96 \mathrm{hrs}$ (red).

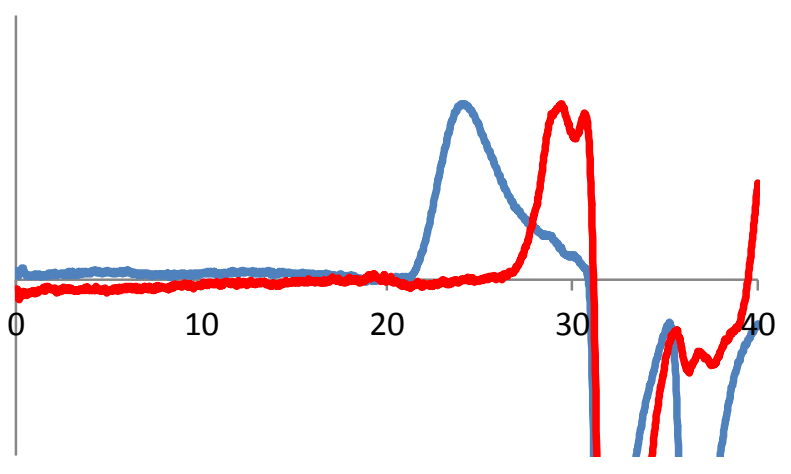




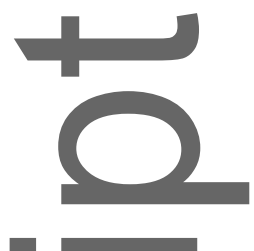

Figure S5. SEC trace of $\mathbf{P 1}$ before degradation, $30 \mathrm{kDa}$, (blue) and following degradation in the presence of 5 eq. of M1, reduction to $2.2 \mathrm{kDa}$ after $96 \mathrm{hrs}$ (red).

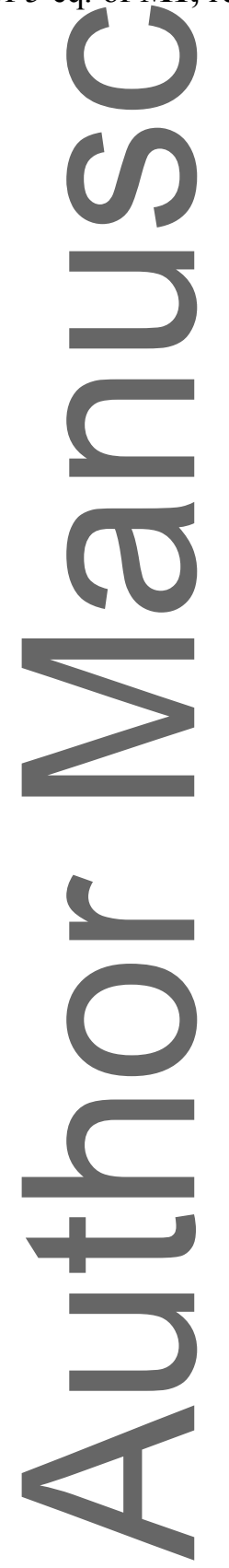




\section{University Library}

\section{- M M N E R VA A gateway to Melbourne's research publications}

Minerva Access is the Institutional Repository of The University of Melbourne

Author/s:

Collins, J;Nadgorny, M;Xiao, Z;Connal, LA

Title:

Doubly Dynamic Self-Healing Materials Based on Oxime Click Chemistry and Boronic Acids

Date:

2017-03-01

Citation:

Collins, J., Nadgorny, M., Xiao, Z. \& Connal, L. A. (2017). Doubly Dynamic Self-Healing Materials Based on Oxime Click Chemistry and Boronic Acids. MACROMOLECULAR RAPID COMMUNICATIONS, 38 (6), https://doi.org/10.1002/marc.201600760.

Persistent Link:

http://hdl.handle.net/11343/292348 